\title{
Pricing Mechanism of China's Trans-regional and Trans-provincial Electricity Trading
}

\author{
Tian Xia ${ }^{1,2}$, ZhiYan Liu ${ }^{1}$, Wei Xiong ${ }^{1}$, YongXiu $\mathrm{He}^{1}$ \\ ${ }^{1}$ School of Economics and Management, North China Electric Power University, Beijing, China \\ ${ }^{2}$ Gansu Electric Power Corporation, Lanzhou, China \\ Email: lzy67821@yahoo.com.cn
}

Received March, 2013

\begin{abstract}
With the large-scale development of Chinese electric power, the contradiction of China's energy supply and demand that reverse distributed is very prominent, therefore, promoting electricity trading is one of the important measures to get optimized configuration of energy resources in nationwide. For the two kinds of trading method, the "power point to the grid" trading and the "grid to grid" trading, this paper designed pricing mechanism model, and took one area as an example, we analyzed the impact of the participants by using different pricing mechanism, and put forward reasonable policy proposals for China's pricing mechanism of trans-regional and trans-provincial electricity trading.
\end{abstract}

Keywords: Trans-regional and Trans-provincial; Electricity Trading; Pricing Mechanism

\section{Introduction}

China's trans-regional and trans-provincial electricity trading has increased year by year. While with the scale enlargement of the trading, some problems happened: the low level of marketization, the imperfect price mechanism, and the unified pricing mechanism which is difficult to meet the interests and the needs of different trading regions and different trading participants, etc. The formation of scientific price mechanism has important significance to promote the development of power trading.

Literature [1] researches the pricing problems of Contract for Differences (CFDs) in the Nordic power trading. Through integrating the power market in South Asia Regional, examining the opportunities, benefits, and challenges, Literature [2] promoted a trans-regional power trading scenario model of South Asia, in this model, the trans-regional power trading price is determined by biding. The studies in Literature [3] show that the convergence of power price can be induced by cross-border and trans-regional electricity trading, and the re-allocation of resources in various countries can be promoted by the optimization of exchange volume and exchange price. Based on the Markal model, Literature [4] assess the effectiveness of the trans-regional power trading between Thailand and Laos, and pointed out that Thailand is expected to gain benefit from the increased level of power imported from Laos in terms of the lower energy system cost, better environmental quality and, greater diversifycation of energy sources. On the basis of an analysis on the price mechanism and methods for power trading between trans-region or trans-provincial grids in China, Literature [5] puts forward some policy recommendations for innovation of power trading price systems and mechanisms in China from different aspects. The characteristics of Chinese cross regional transmission trading price framework are summarized in Literature [6], based on that, the targets of Chinese cross regional trading pricing are proposed, and suggestions on related price framework and mechanism are put forward. Based on the different power supply and demand situation, and the power purchase cost, the price model in trans-regional power consensual dealings, as well as price compliance mechanism are established in Literature [7]. The feed-in tariff, the transmission price, the line loss as well as the sales price are discussed in Literature [8] on the basis of different costs: long-term, medium-term, short-term, accident support as well as spare power to each other. Literature [9] considers that, rational transmission pricing mechanism is a key issue for the development of cross regional electricity trading. The application of the Nash bargaining principle in trans-regional and trans-provincial power trading is studied in Literature [10], aim for maximize the overall effectiveness of the trade subject, the Nash negotiation price model in trans-regional and trans-provincial power trading have been established perceptively. 


\section{Design of Pricing Mechanism for Trans-regional and Trans-provincial Trading}

\subsection{Design of Pricing Mechanism for the "Power Point to Grid” Trading}

\subsubsection{Pricing Mechanism Based on the Operation period Price}

The operation period price, namely inspecting the annual cash flow in project life cycle so as to meet certain financial internal rate of return, that is:

$$
N P V=\sum_{t=0}^{n}\left(C I_{t}-C O_{t}\right)(1+i)^{-t}-B=0
$$

where $N P V$ is the net present value, $C I_{t}$ is the t-th year inflow; $C O_{t}$ is the t-th year outflow; $n$ is the depreciation life, $i$ is internal rate of return, $B$ is the total investment for unit $\mathrm{kW}$.

The transmission pricing mechanism based on the operation period price, namely taking the operation period price as trading price, that is,

$$
P_{a}=P_{j}
$$

where $P_{a}$ and $P_{j}$ is the trading price for transmission side and operation period price for generation companies respectively.

\subsubsection{Pricing Mechanism Based on the Benchmark Price of Coal-fired units of Power Accepted Side}

Currently, in China, benchmark price of coal-fired units of power accepted side in each province (autonomous regions and municipalities directly under the Central Government) based on the operation period price, determined by the average cost of advanced generating sets in the same period.

$$
P_{a}=P_{a, B}
$$

where $P_{a, B}$ is the benchmark price of coal-fired units at transmission side.

\subsubsection{Pricing Mechanism Based on Consultation of Incremental Power Proportion}

The trading price of generator set can maintain the same in utilization time, above that, the price can be set through consultation, and the determination methods include marginal cost pricing, etc. While, the ratio consists of two parts: one is the charge proportion, and the other one is the price ratio of negotiation. The pricing model based on consultation of incremental power proportion is as follows:

$$
\begin{gathered}
P_{a}=K \times P_{a, g}+\theta \cdot(1-K) P_{a, g} \\
K=\frac{Q_{g}}{Q}
\end{gathered}
$$

$$
\text { s.t. } Q \geq Q_{g}
$$

where $P_{a, g}$ is the current tariff at the transmission side, $K$ is the power proportionality coefficient, $\theta$ is the consultation coefficient, and $\theta \leq 1, Q_{g}$ is the transmission quantity in the governments' plan, $Q$ is the total transmission power.

$\theta$ is determined by negotiation between the two sides. From Game theory and Pareto optimal theory we know, $\theta^{*}$, the optimal value of $\theta$, represent the equal incremental profit under negotiations, which being adjusted according to national policies, power supply and demand. The incremental profit distribution is shown as following formulas.

$$
\begin{gathered}
\Delta \pi_{a}=\Delta \pi_{b} \\
\text { s.t. }\left\{\begin{array}{l}
\Delta \pi_{a}=\left(P_{a}-P_{j}\right) \times Q \\
\Delta \pi_{b}=\left(P_{b, B}-P_{a}-P_{\varphi}-P_{\omega}\right) \times Q
\end{array}\right.
\end{gathered}
$$

where, $\Delta \pi_{a}$ and $\Delta \pi_{b}$ are the incremental profit at transmission side and accepted side respectively, $Q$ is the trading volume, $P_{\varphi}$ is the transmission price, $P_{\omega}$ is the line-loss price.

\subsubsection{Pricing Mechanism Based on Consultation of Interests of Price Difference}

Definition 1, "price pushed forward by market": the price is determined by the transmission side.

Definition 2, "price pushed down by market": the price is determined by benchmark price of coal-fired units minus the cost in transmission link.

In this mechanism, by locking the "price pushed forward by market" and the "price pushed down by market" at transmission side, based on the two minimum, generation enterprise's final trading price can be determined through consultation of interests of price difference.

$$
\begin{gathered}
P_{a}=P_{\min }+\theta\left(P_{b, B}-P_{j}-P_{\varphi}-P_{\omega}\right) \\
P_{\min }=\min \left\{P_{j},\left(P_{b, B}-P_{\varphi}-P_{\omega}\right)\right\}
\end{gathered}
$$

where $P_{\min }$ is the minimum of "price pushed forward by market" and "price pushed down by market", $P_{b, B}$ is the benchmark price of coal-fired units at accepted side.

\subsubsection{Pricing Mechanism Based on Negotiation}

In this mechanism, the trading price is determined by the jointly consultation of both sides with considering the market situation, the supply cost and the market risk facrs, etc.

\subsubsection{Pricing Mechanism Based on Competitive Market}

In this mechanism, the trading price is determined by part or full market competition, which is, bid trading patterns. 


\subsection{Design of the Pricing Mechanism for the "Grid to Grid" Trading}

For the "grid to grid" trading, it can also adopt the menoned pricing mechanism except "Pricing mechanism based on the operation period price", and the pricing principles are described as above. However, it is differ in incremental distribution, pricing mechanism at accepted side based on consultation of interests of price difference as well.

Incremental profit distribution of "grid to grid" trading is shown in the following formula.

$$
\begin{gathered}
\Delta \pi_{a}=\Delta \pi_{b} \\
\text { s.t. }\left\{\begin{array}{l}
\Delta \pi_{a}=\left(P_{a}-P_{a, B}\right) \times Q \\
\Delta \pi_{b}=\left(P_{b, B}-P_{a}-P_{\varphi}-P_{\omega}\right) \times Q
\end{array}\right.
\end{gathered}
$$

Pricing mechanism at accepted side based on consultation of interests of price difference is shown in the following formula.

$$
\begin{gathered}
P_{a}=P_{\min }+\theta\left(P_{b, B}-P_{a, B}-P_{\varphi}-P_{\omega}\right) \\
P_{\min }=\min \left\{P_{a, B},\left(P_{b, B}-P_{\varphi}-P_{\omega}\right)\right\}
\end{gathered}
$$

\section{Case Study}

\subsection{Basic Data}

The "power point to the grid" trading took an energy base plant, which owns $2 \times 600$ MW coal-fired units, transmits electricity to A province as an example. For this plant, the coal consumption rate of power supply is $345 \mathrm{~g} / \mathrm{kWh}$, unit annual utilization hours is $5000 \mathrm{~h}$, coal price is 140 yuan/ton, and ROI is $8 \%$. We assume that transmission price is 0.0623 yuan $/ \mathrm{kWh}$ and line-loss price is $0.0167 \mathrm{yuan} / \mathrm{kWh}$. Then analyzing the effect on main participants by using energy base plant electricity substitute for local one, the replacement ratio between $1 \%-3 \%$ and $0.5 \%$ alternative electricity each increase, on the basis of the total electricity purchase in 2011.

The "grid to grid" trading took provinces like B and C transmit electricity to A province as an example. The benchmark price of coal-fired units in these areas are: A province is $0.4142 \mathrm{yuan} / \mathrm{kWh}$, B province is $0.4057 \mathrm{yu}-$ $\mathrm{an} / \mathrm{kWh}$, c province is $0.3179 \mathrm{yuan} / \mathrm{kWh}$. We assume that transmission price in province " $\mathrm{B}$ to $\mathrm{A}$ " " $\mathrm{C}$ to $\mathrm{A}$ " is 0.03 yuan $/ \mathrm{kWh}$ and 0.02 yuan $/ \mathrm{kWh}$, respectively. We also use alternative methods to analysis the effect on main participants.

\subsection{Measurement Results on the "Power Point to the Grid” Trading}

\subsubsection{Pricing Mechanism Based on the Operation Period price}

By formula (1), the operation period price of this plant in the energy base is 0.298 yuan $/ \mathrm{kWh}$, according to formula (2), price at the power transmission side is 0.298 yuan $/ \mathrm{kWh}$, and the power accepted side is 0.377 yuan $/ \mathrm{kWh}$ which is 0.0372 yuan $/ \mathrm{kWh}$ lower than local benchmark price of coal-fired units.

For the power transmission side, that its trading price is 0.0963 yuan $/ \mathrm{kWh}$ lower than local benchmark price of coal-fired units by using this pricing mechanism, not only does it guarantee a reasonable return of investment, but also helps to improve the level of electricity trading, so as to gain more profit. For the power accepted side under this pricing mechanism, when the replacement ratio is between $1 \%$ and $3 \%$, the average electricity purchase price could drop $0.07-0.21$ percent, that the decline in the cost of power purchase is very significant.

\subsubsection{Pricing Mechanism Based on the Benchmark Price of Coal-fired units of Power Accepted Side}

According to formula (3), price at the power transmission side is 0.3179 yuan $/ \mathrm{kWh}$, at the power accepted side is 0.3969 yuan $/ \mathrm{kWh}$ which is 0.0173 yuan/kWh lower than local benchmark price of coal-fired units.

For the power transmission side, if it uses this price as its trading price, the plant would probably reduce its trading size, so as to influence its profit. For the power accepted side under this pricing mechanism, when the replacement ratio is between $1 \%$ and $3 \%$, the average electricity purchase price could drop $0.03-0.10$ percent.

\subsubsection{Pricing Mechanism Based on Consultation of Incremental Power Proportion}

It can be seen from formula (4) - (6) that this mechanism is related with consultation coefficient as well as replacement ratio of electricity. Thus, according to formula (7) - (8), we measured the price in different consultation coefficient as well as replacement ratio at the power transmission side under this pricing mechanism, and the result is shown in Table 1.

For the power transmission side, the essence of this mechanism is to reduce its trading price to get more electricity deal, and certain conditions such as improving unit annual utilization hours could the plant gain a lot of profit. For the power accepted side under this pricing mechanism, when the consultation coefficient is between 0.7 0.9 and the replacement ratio is between $1 \%$ and $3 \%$, the average electricity purchase price could drop $0.04-0.08$ percent. The smaller the consultation coefficient is, the greater the average electricity purchase price would fall.

\subsubsection{Pricing Mechanism Based on Consultation of Interests of Price Difference}

By formula (10) we get the result: $P_{\min }=P_{j}$, that is 0.298 yuan $/ \mathrm{kWh}$. As described above, the optimal value $\theta^{*}$ of 
$\theta$ is 0.5 , according to formula (9), price at the power transmission side is $0.3166 \mathrm{yuan} / \mathrm{kWh}$, at the power accepted side is 0.3956 yuan $/ \mathrm{kWh}$. Taking the changes in market supply and demand into account, the result of consultation may be fluctuated by optimal consultation coefficient. Therefore, we measured the price in different consultation coefficient and the result is shown in Table 2.

For the power transmission side, the trading price is $0.0043-0.0149$ yuan/kWh higher than local benchmark price of coal-fired units, this part is excess profit of energy base plant. For the power accepted side, when the consultation coefficient is 0.5 and the replacement ratio is between $1 \%$ and $3 \%$, the average electricity purchase price could drop $0.04-0.11$ percent. The higher the replacement ratio, the greater the profit gained by both sides.

\subsection{Measurement Results on the "Grid to Grid" Trading}

\subsubsection{Pricing Mechanism Based on the Benchmark Price of Coal-fired units of Power Accepted Side}

As different areas transmit electricity to A province, according to formula (3), price at the power transmission side and accepted side is shown in Table 3.

Price at the power accepted side, when electricity is provided by B province, is $0.0215 \mathrm{yuan} / \mathrm{kWh}$ higher than local benchmark price of coal-fired units; while when electricity is provided by C province is 0.0763 yuan/ kWh lower than local benchmark price of coal-fired units. By contrast, this mechanism makes $\mathrm{C}$ province more competitive in the power trading.

For the power accepted side, when electricity is provided by $\mathrm{C}$ province and the replacement ratio is between $1 \%$ and $3 \%$, the average electricity purchase price could drop 0.2 - 0.6 percent.

\subsubsection{Pricing Mechanism Based on Consultation of Incremental Power Proportion}

According to formula (9), when electricity is provided by $\mathrm{B}$ province, the measured consultation coefficient is greater than 1 , that is conflict with the constraint of $\theta \leq 1$ due to B's benchmark price is higher than A's after deducing transmission costs.

According to formulas (4) - (8) we measured the price in different consultation coefficient as well as replacement ratio at the power transmission side under this pricing mechanism when electricity is provided by $\mathrm{C}$ province, and the result is shown in Table 4.

Table 1. The price based on the consultation of incremental power proportion Unit: yuan/ kWh.

\begin{tabular}{|c|c|c|c|c|c|c|}
\hline Consultation Coefficient & \multicolumn{2}{|c|}{0.7} & \multicolumn{2}{|c|}{0.8} & \multicolumn{2}{|c|}{0.9} \\
\hline Replacement Ratio & transmission side & accepted side & transmission side & accepted side & transmission side & accepted side \\
\hline $1.0 \%$ & 0.3076 & 0.3866 & 0.3110 & 0.3900 & 0.3145 & 0.3935 \\
\hline $1.5 \%$ & 0.3032 & 0.3822 & 0.3081 & 0.3871 & 0.3131 & 0.3921 \\
\hline $2.0 \%$ & 0.2992 & 0.3782 & 0.3055 & 0.3845 & 0.3177 & 0.3907 \\
\hline $2.5 \%$ & 0.2956 & 0.3746 & 0.3031 & 0.3821 & 0.3105 & 0.3895 \\
\hline $3.0 \%$ & 0.2923 & 0.3713 & 0.3099 & 0.3799 & 0.3094 & 0.3884 \\
\hline
\end{tabular}

Table 2. The calculated price results based on the price difference consultations Unit: yuan/ $\mathrm{kWh}$.

\begin{tabular}{cccc}
\hline Consultation Coefficient & 0.4 & 0.5 & 0.6 \\
\hline Price at transmission side & 0.3129 & 0.3166 & 0.3023 \\
Price at accepted side & 0.3919 & 0.3956 & 0.3993 \\
\hline
\end{tabular}

Table 3. The price based on the benchmark price at power transmission side Unit: yuan/ $\mathrm{kWh}$.

\begin{tabular}{ccc}
\hline Measured Price & Provided by B province & Provided by C province \\
\hline Price at transmission side & 0.4057 & 0.3179 \\
Piece at accepted side & 0.4357 & 0.3379 \\
\hline
\end{tabular}

Table 4. The price based on the consultation of incremental power proportion Unit: yuan/ $\mathrm{kWh}$

\begin{tabular}{|c|c|c|c|c|c|c|}
\hline \multirow{2}{*}{$\begin{array}{c}\text { Consultation Coefficient } \\
\text { Replacement Ratio }\end{array}$} & \multicolumn{2}{|c|}{0.7} & \multicolumn{2}{|c|}{0.8} & \multicolumn{2}{|c|}{0.9} \\
\hline & transmission side & accepted side & transmission side & accepted side & transmission side & accepted side \\
\hline $1.0 \%$ & 0.3131 & 0.3331 & 0.3147 & 0.3347 & 0.3163 & 0.3363 \\
\hline $1.5 \%$ & 0.3109 & 0.3309 & 0.3132 & 0.3332 & 0.3156 & 0.3356 \\
\hline $2.0 \%$ & 0.3088 & 0.3288 & 0.3118 & 0.3318 & 0.3149 & 0.3349 \\
\hline $2.5 \%$ & 0.3068 & 0.3268 & 0.3105 & 0.3305 & 0.3142 & 0.3342 \\
\hline $3.0 \%$ & 0.3048 & 0.3248 & 0.3092 & 0.3292 & 0.3135 & 0.3335 \\
\hline
\end{tabular}


For the power accepted side under this pricing mechanism, when the consultation coefficient is between 0.7 0.9 and the replacement ratio is between $1 \%$ and $3 \%$, the average electricity purchase price could drop $0.15-0.17$ percent. The smaller the consultation coefficient is, the greater the average electricity purchase price would fall.

\subsubsection{Pricing Mechanism Based on Consultation of Interests of Price Difference}

As the price difference between $\mathrm{C}$ province and A province is larger, we measured that price at the power transmission side is 0.3560 yuan $/ \mathrm{kWh}$ which is $0.0382 \mathrm{yu}-$ $\mathrm{an} / \mathrm{kWh}$ lower than local benchmark price of coal-fired units, at the power accepted side is $0.3760 \mathrm{yuan} / \mathrm{kWh}$ which is 0.0382 yuan/kWh lower than local benchmark price of coal-fired units.

For the power accepted side, when the consultation coefficient is 0.5 and the replacement ratio is between $1 \%$ and $3 \%$, the average electricity purchase price could drop 0.10 - 0.30 percent. The higher the replacement ratio is the greater profit it gained.

\section{Conclusions}

Establish a reasonable pricing mechanism is one of the core issues in China's trans-regional and trans-provincial electricity trading. For the "power point to the grid" trading and the "grid to grid" trading, in this paper we draw the conclusions as follows:

1) The pricing mechanism based on operation period price ensures the power generation companies' recovery of the cost, is the most competitive trading price compared to other pricing mechanism of "power point to the grid” trading, thus, it is suitable for energy base power trading.

2) The pricing mechanism based on consultation of incremental power proportion considers the fairness of the planned trading and the flexibility of the unplanned trading benefit both sides at the same time. It is suitable for the "grid to grid" trading.

3) As for the pricing mechanism based on consultation of interests of price difference, its essence is the reasonable distribution of the price difference and suitable for the "grid to grid" trading.

4) The pricing mechanism based on negotiation as well as the pricing mechanism based on competitive market could reflect the actual market situation better, thus they apply to the electricity trading at the mature stage of the market. Before that, the above pricing mechanism can be used as a useful transition.

\section{Acknowledgements}

The work described in this paper was supported by the National Natural Science Foundation of China (Grant No. 71273089) and Beijing Natural Science Foundation of China (Grant No.9122022)

\section{REFERENCES}

[1] T. Kristiansen, "Pricing of Contracts for Difference in the Nordic market,” Energy Policy, Vol. 32, No. 9, 2004, pp. 1075-1085. doi:10.1016/S0301-4215(03)00065-X

[2] S. Saroha and R. Verma, "Cross-border Power Trading Model for South Asian Regional Power Pool,” International Journal of Electrical Power \& Energy Systems, Vol. 44, No. 1, 2013, pp. 146-152. doi:/10.1016/j.ijepes.2012.07.007

[3] L. Parisio and B. Bosco, "Electricity Prices and Cross-border Trade: Volume and Strategy Effects," Energy Economics, Vol. 30, No. 4, 2012, pp. 1760-1775. doi:10.1016/j.eneco.2008.01.002

[4] M. Watcharejyothin and R. M. Shrestha, "Effects of Thailand: Energy Security and Environmental Implications," Energy Policy, Vol. 37, No. 5, 2009, pp. 1782-1792. doi:10.1016/j.enpol.2008.12.021

[5] H. Q. Zheng, Price System and Mechanism Innovation for Electricity Trading between Trans-region or Trans-province Grids in China,” Electric Power Technologic Economics, Vol. 23, No. 12, 2011, pp. 74-77.

[6] M. Zeng, J. C. Chu, P. J. Yang, et al., Research on Price Framework and Mechanism for Chinese Cross-regional Transmission Trading,” East China Electric Power, Vol. 37, No. 11, 2009, pp. 1795-1798.

[7] H. Q. Zheng, "Study on Pricing Model of Power Negotiated Electricity Trading between Trans-region or Trans-province Grids in China,” China Price, Vol. 10, No. 3, 2010, pp. 48-50.

[8] L. H. Wang, J. H. Wang and C. S. Xie, "Research on Trans-regional Power Transmission Prices,” North China Electric Power, Vol. 10, 2003, pp. 17-20.

[9] Q. R. Wang, L. Z. Zhang and G. H. Xie, “A Transmission Pricing Mechanism for Cross-regional Electricity Trading,” Automation of Electric Power Systems, Vol. 34, No. 13, 2010, pp. 11-15.

[10] H. Xia and G. H. Zeng, "Pricing Mechanism of Electricity Trading between Trans-region or Trans-province Based on Nash Equilibrium Consultation," China Electric Power Education, Vol. 12, No. 2, 2011, pp. 103-106. 